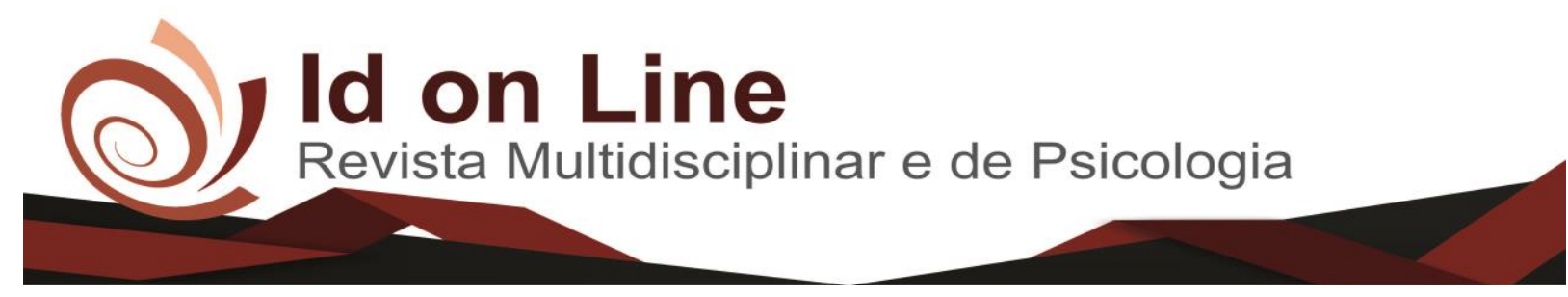

Estudo de Caso

\title{
Avaliação da Pedagogia Narrativa no Curso de Bacharelado em Enfermagem na Universidade Regional do Cariri - URCA
}

\author{
Fabiano Martins Teixeira ${ }^{l}$
}

\begin{abstract}
Resumo: As abordagens do ensino convencional centradas sobre a cobertura de conteúdo, não são mais adequadas nas graduações de enfermagem, com as habilidades cognitivas e afetivas necessárias para funcionar nos papéis desafiadores da prática dessa profissão. O objetivo deste estudo fenomenológico foi explorar as experiências de educadores que usaram Pedagogia Narrativa para ensinar conceitos de enfermagem e tópicos. Procurou entender como os educadores avaliaram os resultados da aprendizagem dos alunos após a promulgação desse tipo de Pedagogia. As questões da pesquisa foram as seguintes: (1) Atingiu-se o objetivo desejadoapós a promulgação da Pedagogia Narrativa? e (2) Quais são os métodos de avaliação e que ferramentas são mais apropriados para medir os resultados dos alunos após? Participaram oito professores do curso de enfermagem da Universidade Regional do Carri - Unidade Descentralizada do Iguatu - Ceará, que tinham recentemente utilizado a Pedagogia Narrativa para preparar os estudantes de enfermagem. Os dados foram analisados, sintetizados e interpretados usando um interativo, trifásico não linear usando a hermenêutica de Heidegger e estatísticas descritivas. Três grandes temas, relacionados com a avaliação da Pedagogia Narrativa surgiram: (a) determinar o uso da Pedagogia Narrativa, (b) melhorar os resultados dos alunos, e (c) determinar métodos de avaliação e ferramentas. Os resultados certamente contribuirão para uma reforma do ensino de enfermagem, relacionada às decisões pedagógicas dos educadores.
\end{abstract}

Palavras-Chave: Ensino de enfermagem - Pedagogia narrativa - Aprendizagem

\section{Narrative Education Assessment in Nursing Degree Course in Regional University of Cariri - URCA}

\begin{abstract}
Conventional approaches focused on content coverage are no longer appropriate in nursing degrees, with the cognitive and affective skills needed to function in the challenging roles of nursing practice. The objective of this phenomenological study was to explore the experiences of educators who used Narrative Pedagogy to teach nursing concepts and topics. It sought to understand how educators evaluated the learning outcomes of students after the promulgation of this type of Pedagogy. The research questions were as follows: (1) Was the desired goal reached after the enactment of Narrative Pedagogy? and (2) What are the assessment methods and what tools are most appropriate to measure student outcomes after? Participants were eight teachers from the nursing course of the Regional University of Carri - Decentralized Unit of Iguatu - Ceará, who had recently used Narrative Pedagogy to prepare nursing students. Data were analyzed, synthesized and interpreted using an interactive, non-linear threephase using Heidegger's hermeneutics and descriptive statistics. Three major themes related to the evaluation of Narrative Pedagogy emerged: (a) to determine the use of Narrative Pedagogy, (b) to improve students' results, and (c) to determine assessment methods and tools. The results will certainly contribute to a reform of nursing education, related to the pedagogical decisions of educators.
\end{abstract}

Keywords: Nursing Education - Narrative Education - Learning

\footnotetext{
${ }^{1}$ Graduado e Licenciado em Enfermagem, Especialista em Docência do Ensino Superior e em Saúde da Família, Mestre em Ciências da Educação. Coordenador local do Curso de Gestão em Saúde Pública da Universidade Regional do Cariri. Enfermeiro no Hospital Regional de Iguatu e na Estratégia Saúde da Família do Município de Cariús. Docente em Cursos Técnicos em Enfermagem e de Gestão em Saúde Pública.
} 


\section{Introdução}

As estratégias de ensino convencionais ainda são rotineiramente utilizadas no ensino de enfermagem e são vistos como inadequada a enfrentar os desafios curriculares que são consequiência da constante mudança no ambiente de saúde. Acadêmicos de enfermagem e organizações profissionais, como COREN - Conselho Regional de Enfermagem pediram programas de educação de enfermagem para rever currículos para enfrentar os desafios da prática. Além disso, o referido conselho recomendou desenvolvimento, implementação e avaliação do estudante. A fim de atender as chamadas para a reforma e preparar os formandos de enfermagem para o ambiente complexo de saúde, educadores estão tentando novas pedagogias criativas.

Estas novas pedagogias devem ser baseada em evidências e capazes de atender às necessidades tanto dos educadores como dos educandos. APedagogia Narrativa, sendo uma pedagogia criativa, é capaz de complementar as pedagogias convencionais, no entanto, são necessárias mais provas para determinar comoos estudantes de enfermagem estão para atingir resultados de aprendizagem desejados após a promulgação da Pedagogia Narrativa.

O objetivo deste estudo foi explorar as experiências de educadores que usaram a Pedagogia Narrativa para ensinar conceitos de enfermagem e tópicos. Este estudo procurou entender comoos educadores avaliaramos resultados da aprendizagem dos alunos após a promulgação desse tipo de pedagogia.

Embora muito se saiba sobre Pedagogia Narrativa, que ainda não é amplamente utilizado na educação em enfermagem, o estado atual do ensino de enfermagem permanece focado no resultado. Os resultados dos alunos são de extrema importância e são utilizados como medidas de qualidade de programas educacionais.

Educadores de enfermagem continuam a questionar quais as abordagens para o ensino e a aprendizagem que vai ajudar os alunos a alcançarem os muitos resultados impostos, metas e expectativas. (IRONSIDE, 2003).

Além disso, os resultados vão continuar o diálogo relacionado à reforma do ensino de enfermagem entre educadores, administradores, estudantes e outros interessados.

\section{A Pedagogia Narrativa}

Para facilitar a reforma, os educadores de enfermagem adotaram pedagogias interpretativas como suplementos para pedagogias convencionais. Ambas as abordagens pedagógicas, embora de 
pontos de vista fundamental, são benéficas para o ensino de enfermagem (DIEKELMANN, 2001; DIEKELMANN e DIEKELMANN, 2009).

As Pedagogias Interpretativas devem promover a aprendizagem de conteúdos de enfermagem através do pensamento multi-perspectivo e incentivar os alunos e professores para interpretar e desenhar seus próprios significados de aprender experiências (IRONSIDE, 2003). A Pedagogia Narrativa, desenvolvida por Diekelmann em 1995, é uma pedagogia interpretativa que destaca as experiências vividas e compartilhadas de alunos e professores por meio da crítica, e fenomenológica, bem como, as abordagens convencionais, ao ensino e à aprendizagem (DIEKELMANN, 2001; IRONSIDE, 2006). Ela é específica para a educação de enfermagem e implica a utilização de estudantes, de professores, médicose dos doentes ou casos paradigmáticos, assim, ver muitos meios e métodos para criar um ambiente de aprendizagem onde os alunos e professores troquem diálogo sobre as suas experiências (DIEKELMANN e DIEKELMANN, 2009) .

Através da utilização de narrativas, os alunos têm a oportunidade de pensar, refletir e analisar os problemas, soluções e outras questões relacionadas com o curso em si. Um exemplo da promulgação da Pedagogia Narrativa é um educador de enfermagem pedindo aos alunos para escrever uma história descrevendo as suas experiências de como cuidar de um paciente diagnosticado com hipertensão. Os alunos lêem suas narrativas para os outros na classe e discutemexperiências comuns em narrativas, psicológica, física, socioeconômicos e questões ambientais, para citar alguns. Pedagogia Narrativa é muitas vezes comparada a narrativa que tem sido utilizado na educação ao longo de décadas. No entanto, Diekelmann (2001) afirmou que ele não está usando contação de histórias como uma estratégia para a aprendizagem, em vez disso, a pedagogia como Narrativa tende a compartilhar e interpretar narrativas contemporâneas que é uma chamada para os alunos e professores de forma que possuem tudo em aberto e problemático. $\mathrm{O}$ ambiente de aprendizagem é descrito como uma comunidade de alunos e todos os participantes - professores e alunos - estão envolvidos no desenvolvimento, implementação e avaliação (NEHLS, 1995).

\section{Metodologia}

O objetivo deste estudo f foi explorar e encontrar significado nas experiências de ensino de educadores que promulgaram Pedagogia Narrativa para ensinar conceitos de enfermagem e tópicos. Este estudo buscou compreender como os educadores avaliaram os alunos e os resultados de aprendizagem após a promulgação da Pedagogia Narrativa. Este capítulo irá fornecer detalhes relacionados com o 
projeto de pesquisa, seleção dos participantes e coleta e análise de dados métodos. Suposições do pesquisador e considerações éticas também são discutidas.

Este estudo utilizou uma abordagem fenomenológica interpretativa para obter dados sobre as experiências de educadores de enfermagem que utilizaram a Pedagogia Narrativa. Mais especificamente, o pesquisador utilizou a fenomenologia hermenêutica de Heidegger. A fenomenologia é um apropriado para aproximar e estudar esta pedagogia interpretativa, uma vez que examina a essência de um fenômeno desconhecido (POLIT e BECK, 2008).

A fenomenologia hermenêutica procura explorar e encontrar significado do fenômeno, uma vez que é vivida por aqueles que estão envolvidos (CRIST e TANNER, 2003). Foi importante para o pesquisador ir além descrevendo educadores de enfermagem, experiências com Pedagogia Narrativa para interpretar e encontrar significado em suas experiências.

\section{Pressupostos do pesquisador}

De acordo com as tradições da fenomenologia hermenêutica de Heidegger,os pressupostos do pesquisador são divulgados. Experiências anteriores do pesquisador situam o ponto de vista em que estas interpretações serão feitas e é chamado de ponto de vista. Hipóteses preconcebidas ou interpretações, também com base em experiências e crenças anteriores do pesquisador, são rotuladas como ponto de concepção (BENNER, 1994). É discutido cada aspecto da estrutura do pesquisador de entendimento.

O pesquisador é um educador de enfermagem e tem experiência de ensino em uma pequena universidade do Centro Sul do Estado do Ceará. O pesquisador tem experiência de ensino na sala de aula tradicional, clínicas e ambientes de aprendizageme tem usado pedagogias convencionais e Pedagogia Narrativa. Além disso, o pesquisador tem experiência com o uso de vários instrumentos de avaliação convencionais e não convencionais.

O pesquisador estava situado em várias posições ao longo do estudo, mas nunca como um observador objetivo. Estas posições oscilaram entre o pesquisador como membro imaginativode mundo dos participantes para o pesquisador como um observador (BENNER, 1994). O pesquisador abordado neste estudo, do ponto de vista de um educador de enfermagem e olhou para novas idéias para resolver os velhos problemas que cercam os currículos de enfermagem.

Esta posição teve um impacto sobre a forma como o pesquisador via e interpretava os dados. Como um defensor da reforma do ensino de enfermagem, o pesquisador está à procura de estilos pedagógicos e ferramentas que irão influenciar a mudança na área da educação em enfermagem. 
O pesquisador acredita que o ensino na academia requer um membro da faculdade de se envolver em papéis multifacetados. Filosofia de ensino do pesquisador é influenciada por princípios de ordem social construtivista e está centrada no facilitador como sendo o papel mais importante de professores de enfermagem.

A Pedagogia convencional não facilita o desenvolvimento da empatia, cultural sensibilidade, ou pensamento de multiperspectiva. O pesquisador acredita que o exame convencional e avaliação limitada ao currículo de enfermagem reforçam como educadores de enfermagem estão preocupados com a capacidade dos alunos para ser bem sucedido nestes exames se eles usaram estratégias de ensino não convencionais. Ferramentas de avaliação convencionais podem apenas medir a aquisição de conhecimento e muitas vezes são culturalmente tendencioso. $\mathrm{O}$ pesquisador prevê-se que aqueles educadores que usaram métodos de avaliação alternativos iria relatar mais satisfação em atender seus objetivos instrucionais e medir os resultados do aluno.

Amostragem ou critério de amostragem intencional foi usado para recrutar professores de enfermagem que atualmente tem usado mais recentemente a Pedagogia Narrativa para ensinar temas ou conceitos de enfermagem. Este tipo de amostragem seleciona os melhores informantes que tiveram experiência com o fenômeno e rendimentos para melhor responder às questões de pesquisa de um estudo (POLIT e BECK, 2008; RUDESTAM e NEWTON, 2007).

Também foi utilizada amostragem bola de neve. Essa amostragem permitiu ao pesquisador de obter os nomes e informações de contato de outros potenciais participantes.

Os candidatos participantes foram recrutados por referências da direção da universidade, e outros educadores de enfermagem. Professores manifestaram interesse neste estudo e compartilhado resumo do estudo e informações de contato do pesquisador com os educadores de enfermagem que usaram Pedagogia Narrativa.

A amostra foi composta de oito participantes. Os critérios de inclusão da amostra era (1) ser capaz de falar e escrever em Português, (2) ter 25 anos ou mais de idade, (3) ser um enfermeiro, (4) ser um professor de enfermagem, e (5) ter experiência mínima de um ano usando a Pedagogia Narrativa.

Foram empregados todos os esforços para impedir o dano ou risco de dano aos participantes do estudo. A participação foi voluntária e os participantes tiveram a opção de se retirar do estudo a qualquer momento. Além disso, a participação sem nenhum custo para os participantes nem foram compensados.

Todos os potenciais participantes foram contactados via e-mail pelo pesquisador que incluiu uma breve explicação do estudo e um pedido de dados demográficos. Se potenciais participantes preencheram os critérios de inclusão do estudo e ficou interessado em participar, o pesquisador em contato com eles para agendar uma entrevista. Um formulário de consentimento informado foi enviado por email. 


\section{Amostra}

Constou de 8 participantes, que atenderam os critérios de inclusão. Estes os participantes tiveram o maior número de anos de experiência usando Pedagogia Narrativa. Todos os participantes foram Mulheres brancas, com idades variando de 25 a 65 anos de idade. Todos eram experientes educadores de enfermagem, empregadas em tempo integral no nível de universidade. Seus anos de experiência de educação de enfermagem variou 05-15 anos. Cada um também trouxe vários níveis de experiência com a Pedagogia Narrativa, compreendido entre 2 e 10 anos de experiência.Os participantes relataram-se ensinando em vários cursos de enfermagem usando Pedagogia Narrativa incluindo o seguinte: (a) saúde da mulher, (b) pediatria, (c) médico-cirúrgica, (d) fundações / fundamentos, (e) avaliação física / saúde, (f) modos de investigação, (g) a gestão clínica, (h) de enfermagem transições, (i) cruzamento cultural, e (j) a sexualidade humana. Ver Tabela 1 para um resumo do demográfico da amostra.

\section{Geração de Dados}

A coleta de dados começou em maio de 2013 e continuou até setembro de 2013. O pesquisador utilizou entrevistas semi-estruturadas e análise de documentos para coletar dados, a entrevista guia / protocolo foi desenvolvido usando as grandes linhas de investigação e terminou por abrir uma sondagem a perguntas para garantir adequada investigação. O protocolo também incorporou alguns dos princípios do construtivismo social, questionando a forma como os educadores facilitou a aprendizagem e garantiu que aprendizagem era um processo social onde os alunos interagiram.

Durante a entrevista inicial, os participantes foram convidados a fornecer cópias de seus currículos, "narrativas dos alunos, submissões de atribuição, instruções de atribuição, e / ou outras ferramentas de avaliação". Esses itens foram coletados após a entrevista por e-mail ou correio. Houve uma segunda entrevista, para dirimir dúvidas sobre osdocumentos apresentados.

Análise de dados, síntese, interpretação, transcrições, notas da entrevista e documentos apresentados pelos participantes foram manualmente revistos e analisados pelo pesquisador. Os documentos apresentados foram analisados com as transcrições e notas da entrevista para ajudar a ilustrar e entender como Pedagogia Narrativa foi promulgada e avaliada. Análise e interpretação dos dados teve início após a primeira entrevista e continuou durante toda a coleta de dados. Após cada entrevista, o pesquisador analisou os dados antes de se iniciar a próxima entrevista. Creswell (2009) 
descreveu o processo de análise de dados como um ciclo contínuo e entrelaçadas de coleta, organização, reflexão, interpretação e escrita.

Um processo não linear iterativa de três fases, adaptado a partir de Benner (1994) e Crist e Tanner (2003), foi usado para analisar os dados. Estatísticas descritivas também foramutilizadas para descrever a amostra, vários documentos, métodos de avaliação e ferramentas de avaliação.

Tudo começou com a leitura de cada transcrição pesquisada e dados relacionados várias vezes para obter uma compreensão holística dos dados. Benner (1994) afirmou nesta fase é onde o plano interpretativo é desenvolvido eo pesquisador pode achar que é necessário alterar ligeiramente as linhas de inquérito, a fim de tratar de questões que surgem a partir dos dados. Crist e Tanner (2003) acrescentou que a avaliação crítica das técnicas de entrevista deve ocorrer durante a primeira fase. Enquanto alternando entre textos inteiros, parte de textos e análises, o pesquisador procurou temas significativos, padrões e preocupações.

Na segunda fase da análise dos dados, depois de identificar temas, o pesquisador procurou trechos das transcrições para melhor ilustrar os temas. Para fazer isso, o pesquisador escolheu situações específicas e analisados diversos aspectos da situação para incluem respostas dos participantes, ações e preocupações (BENNER, 1994).

Isto revelou exemplares ou "trechos marcantes que caracterizam temas comuns específicos ou significados através informantes"(CRIST e TANNER,2003, p. 204).

Durante a terceira fase, depois de reunir exemplares, o pesquisador focado em comuns significados ou casos paradigmáticos entre as entrevistas.

"Casos paradigmáticos deinformações descritivas necessárias para compreender como as ações de um indivíduo e entendimentos emergem a partir de seu contexto situacional: as suas preocupações, práticas e significados de fundo"(Benner,1994, p. 59).

Os resultados finais foram alcançados por meio da revisão manuscrita das notas, cartões de índice, os documentos apresentados, e as transcrições integrais.

\section{Medidas de Qualidade}

Os estudos qualitativos não contam com os mesmos critérios para avaliar e garantir a qualidade como estudos quantitativos.Validade, confiabilidade e generalização não se encaixam de forma adequada com os fundamentos filosóficos da fenomenologia (BENNER, 1994). Estas medidas se ajustamaos pontos de vista do modelo cartesiano que colocam mais ênfase na objetividade e realismo, 
que contraste com os pontos de vista da fenomenologia de Heidegger (BENNER, 1994). Mais ainda, hermenêutica dos estudos não seguem as mesmas estratégias de rigor como estudos com abordagens positivistas (BENNER, 1994).

Para garantir a qualidade deste estudo foram utilizadas as seguintes estratégias: verificação de membro, esclarecimento de preconceitos do pesquisador, e uma trilha de auditoria. O feedback dos participantes relacionados a temas emergentes e os resultados foram ativados através do envio de um cópia de transcrições das entrevistas iniciais dos participantes com interpretações iniciais do pesquisador.

Os participantes foram convidados a retornar a transcrições e seus comentários para o pesquisador. Uma estratégia de credibilidade, é usado para garantir interpretações do pesquisador de experiências dos participantes não se afastam muito longe os significados reais dos participantes (CRESWELL, 2009). Outra estratégia para melhorar a credibilidade dos resultados éa tempestade de ideias. Pressupostos e preconceitos do pesquisador são discutidos nesta dissertação como outra estratégia para promover a qualidade dentro do estudo. Esta transparência é importante para melhorar confiabilidade (RUDESTAM e NEWTON, 2007).

Por último, uma trilha de auditoria foi mantida através de métodos manuscritos, o pesquisador manteve um profundo registro de eventos durante todo o estudo para incluir passos de reflexões do estudo, pesquisador, e como foram analisados os dados (RUDESTAM e NEWTON, 2007).

Tabela 01 - Resumo da Demografia da Amostra

\begin{tabular}{|c|c|c|c|c|c|c|c|c|}
\hline & Part 01 & Part 02 & Part 03 & Part 04 & Part 05 & Part 06 & Part 07 & Part 08 \\
\hline Idade & $25-35$ & $45-55$ & $55-65$ & $35-45$ & $55-65$ & $45-55$ & $35-45$ & $35-45$ \\
\hline Título & $\begin{array}{l}\text { Professor } \\
\text { Contratado }\end{array}$ & $\begin{array}{l}\text { Professor } \\
\text { Contratado }\end{array}$ & $\begin{array}{l}\text { Professor } \\
\text { Efetivo }\end{array}$ & $\begin{array}{l}\text { Professor } \\
\text { Contratado }\end{array}$ & $\begin{array}{l}\text { Professor } \\
\text { Efetivo }\end{array}$ & $\begin{array}{l}\text { Professor } \\
\text { Contratado }\end{array}$ & $\begin{array}{l}\text { Professor } \\
\text { Contratado }\end{array}$ & $\begin{array}{l}\text { Professor } \\
\text { Contratado } \\
\end{array}$ \\
\hline $\begin{array}{l}\mathrm{N}^{\circ} \text { de Anos } \\
\text { como } \\
\text { Professor do } \\
\text { Curso de } \\
\text { Enfermagem }\end{array}$ & 7 & 15 & 20 & 12 & 15 & 12 & 10 & 8 \\
\hline $\begin{array}{l}\mathrm{N}^{\circ} \text { de Anos } \\
\text { utilizando a } \\
\text { Pedagogia } \\
\text { Narrativa }\end{array}$ & 2 & 8 & 10 & 8 & 10 & 7 & 9 & 3 \\
\hline
\end{tabular}




\begin{tabular}{|c|c|c|c|c|c|c|c|c|}
\hline $\begin{array}{l}\text { Última Vez } \\
\text { que usou a } \\
\text { Pedagogia } \\
\text { Narrativa }\end{array}$ & 2013 & 2013 & 2013 & 2013 & 2013 & 2013 & 2013 & 2013 \\
\hline $\begin{array}{l}\text { Disiplina } \\
\text { Ministrada } \\
\text { utilizando a } \\
\text { Pedagogia } \\
\text { Narrativa }\end{array}$ & $\begin{array}{l}\text { Saude da } \\
\text { Mulher, } \\
\text { Saúde do } \\
\text { Adulto e } \\
\text { Saúde da } \\
\text { Criança e } \\
\text { Práticas } \\
\text { Familiares }\end{array}$ & $\begin{array}{l}\text { Gestão, } \\
\text { Pediatria e } \\
\text { Avaliação } \\
\text { Médico } \\
\text { Cirurgico } \\
\text { em } \\
\text { Enferma- } \\
\text { gem }\end{array}$ & $\begin{array}{l}\text { Fundamen- } \\
\text { tos em } \\
\text { Enferma- } \\
\text { gem }\end{array}$ & $\begin{array}{l}\text { Fundamen- } \\
\text { tos em } \\
\text { Enferma- } \\
\text { gem }\end{array}$ & $\begin{array}{l}\text { Fundamen- } \\
\text { tos em } \\
\text { Enferma- } \\
\text { gem }\end{array}$ & $\begin{array}{l}\text { Sexualidade } \\
\text { Humana }\end{array}$ & $\begin{array}{l}\text { Saúde da } \\
\text { Mulher }\end{array}$ & $\begin{array}{l}\text { Práticas em } \\
\text { Enfermage } \\
\mathrm{m}\end{array}$ \\
\hline
\end{tabular}

Fonte: Pesquisa.

\section{Resultados}

Utilizando os princípios da fenomenologia heideggeriana, o construtivismo da epistemologia e o construtivismo social, o pesquisador analisou as experiências vividas dos educadores de enfermagem, avaliação dos resultados de aprendizagem após a sua promulgação de Pedagogia Narrativa.

Após a análise, síntese e interpretação dos dados, três temas, relacionados com a avaliação da Pedagogia Narrativa, surgiram: (a) determinar o uso da Pedagogia Narrativa, (b) melhorar os resultados dos alunos desejados, e (c) o que determina os métodos de avaliação adequados e ferramentas. Os resultados apresentados por este estudo foram expostos pelas questões de pesquisa: Quais são os resultados de aprendizagem desejados seguindo a Pedagogia Narrativa? E métodos de avaliação que ferramentas são mais apropriados para medir os resultados dos alunos? A discussão a seguir explicita as conclusões do investigador e temas emergentes. Os resultados são apresentados via narrativas para exemplificar os temas e estatística descritiva.

\section{Resultados do trabalho}

Determinando uso da Pedagogia Narrativa apresentou-se como a mais pertinente e influente tema para as linhas de investigação e descobertas. A compreensão da Pedagogia Narrativa era dicotômica entre os participantes. Ele foi usado como uma filosofia global de ensino ou uma estratégia de ensino complementar. 
Dos oito participantes, cinco entendiam a Pedagogia Narrativa como uma abrangente filosofia que guiou suas abordagens de ensino e aprendizagem. Eles estavam inflexíveis entendendo que a Narrativa Pedagogia era mais do que um método de ensino ou estratégia. Além disso, eles enfatizaram a importância de determinar como Pedagogia Narrativa foi compreendida e promulgada. Esta afirmação é evidente no seguinte trecho de um participante que teve mais de 10 anos de experiência promulgação Pedagogia Narrativa.

É verdade que as histórias são narrativas, mas tem que haver algo mais que rodeia a história, a fim de que ela seja enquadrada como Pedagogia Narrativa.

Não são as estratégias que fazem a Pedagogia Narrativa, mas sim, são as situações que a cercam. Outro participante, cuja compreensão que a Pedagogia Narrativa era centrada na narrativa-ensino e mais tarde mudou após mais pesquisas, falou sobre seu entendimento da mesma:

\footnotetext{
"Meu entendimento da Pedagogia Narrativa é que ele vai aparecer diferente dependendo da configuração em que ele é usado e também quem está convidando ou quem está usando. Eu não vejo isso como uma estratégia tanto como uma filosofia ou um paradigma, uma abordagem para o ensino ou aprender".
}

Ele pode usar histórias ou narrativas no ambiente de aprendizagem ou não, mas o que é mais importante é que o espaço é criado, onde professores e alunos se sintam confortável e seguro para ser capaz falar sobre o que está indo bem e o que não está indo bem.

Este participante, muitas vezes usou a frase "convidando a Pedagogia Narrativa na sala de aula", como ela discutiu sua promulgação de Pedagogia Narrativa. Os participantes, que usam Pedagogia Narrativa como uma filosofia abrangente faz uma distinção entre o ensino ea narrativa centrada na Pedagogia Narrativa.

As coisas que cercam a história são inclusivas de promover a abertura na aprendizagem ambiente e criação de parcerias entre alunos e professores para uma comunidade de pensadores interpretativa. Estes participantes haviam adotado Pedagogia Narrativa e promulgou-o em tudo aulas que ensinavam. Além disso, o conteúdo dos seus cursos não era o único foco de cada classe. A participante com experiência de mais de 16 anos de promulgação da Pedagogia Narrativa fez a seguinte declaração:

\footnotetext{
"Eu quero dizer que este não é definitivamente sobre o conteúdo. Eu não me preocupo com o conteúdo que eu escolhi para ministrar as aulas, mas como os meus alunos trataram seus pacientes, porque eu sei que eles têm problemas interessantes, mas eu não pretendo avaliá-los pelo conteúdo específico que eles vão apresentar, porque na maioria das vezes eu não ia saber o que eles vão dizer. Sei que eles têm problemas particulares e que eles são narrativamente pessoas ativas, mas espero que eles vão contar a história no entanto, vem a eles e eu não tenho controle disso. Então, quando
} 
eu faço um esboço de curso, eu não sei qual é o resultado do curso, não há esboço do que é ensinado, até que o curso seja feito.”

Para ajudar a determinar o teor de curso, este participante pedia aos estudantes, no início do curso,para determinar suas próprias metas de aprendizagem. No fim do curso, os estudantes foram convidados a preencher uma auto-avaliação da sua aprendizagem.

\section{Estratégia Suplementar}

Os outros três participantes tiveram um entendimento diferente da Pedagogia Narrativa. Sua discussão sobre Pedagogia Narrativa descrevia o uso da pedagogia como um ensino suplementar de estratégia. Todos eles usaram narrativas para ter como método de ensino a Pedagogia Narrativa. Um participante que ensinou um curso de enfermagem médico-cirúrgica tinha a dizer sobre o uso de Pedagogia Narrativa que era uma forma revolucionária para se ensinar um curso.

No ensino de enfermagem médico-cirúrgica, não sinto que seria apropriado. Eu acho que, se nós falamos sobre cursos onde falamos sobre a arte e a ciência de enfermagem, liderança de enfermagem, ou temos uma classe chamada, formas de saber, como a intuição dos enfermeiros, profisssionalismo coisas como essa você definitivamente pode ensiná-lo na Pedagogia Narrativa.

As diferenças na compreensão dos participantes sobre Pedagogia Narrativa são definitivamente reconhecíveis na forma como ela é promulgada e avaliada. Os participantes que viram Pedagogia Narrativa como uma filosofia abrangente utilizando vários métodos e ferramentas, incluindo os convencionais, a avaliar a aprendizagem.

A maioria não percebe muita diferença na avaliação de pedagogias convencional Narrativa ou Pedagógica. Aqueles que viram Pedagogia Narrativa como uma estratégia suplementar solicitaaos alunos a escrever uma história sobre um tópico. Estas narrativas foram usadas em sala de aula para transmitir informações relacionadas com o tema. A maioria dos estudantes obrigados a ler em voz alta na classe narrativa e uma discussão seguido.

Estes participantes avaliaram principalmente se o aluno atingiu os resultados da aprendizagem através da avaliação e discussão dessas narrativas e exames convencionais. Eles expressaram um o desejo de ter ferramentas mais concretas para a construção dessas narrativas, como uma lógica abrangente, assim, melhorar os resultados dos alunos.

Embora a compreensão dos participantes sobre Pedagogia Narrativa é variada, os resultados dos alunos, tinha muitos pontos em comum. Os resultados dos alunos desejados descritos pelos participantes eram principalmente de domínios cognitivos e afetivos. Inúmeros foram os resultados dos alunos 
discutidos, mas o mais prevalente incluído o desejo para os alunos (a) utilizar diferentes tipos de pensamento, (b) prestação de cuidados individualizados centrados no paciente, (c) ser melhores ouvintes, (d) compreender conceitos e conteúdo, (e) reconhecer semelhanças em todo pacientes, (f) ser melhor em comunicação oral e escrita, e (g) tomar decisões éticas e reconhecer comportamentos antiéticos.

\section{Reconhecer Semelhanças em todos os Pacientes}

Embora os participantes quisessem alunos que fossem capazes de fornecer assistência centrada no paciente, eles também queriam que os alunos reconhecessem as semelhanças através pacientes. Os participantes acreditavam e isso permitiu que os alunos compreendessem melhor as experiências compartilhadas de doentes, estudantes, enfermeiros, e outros. Um dos participantes com mais de 16 anos de experiênciana Pedagogia Narrativa descreveu como estudantes exibiram essa capacidade durante a aula de discussão de narrativas. Acho que o que é interessante é que em todo o resto do semestre os alunos remetem para as histórias. Eles vão dizer: "Professora, isso que esta dizendo é como a história que você contou no primeiro dia da disciplina, essa estória me lembra da mulher que estavam cuidando". "Eles são ... não tão bom no começo, mas até o final do semestre, eles começam a conectar as histórias".

Participantes usaram narrativas orais e escritas como ferramentas de ensino para ajudar os alunos a observar comuns questões entre as populações, processos de doença, e configurações. Eles afirmaram que centrada na narrativa do ensino fez aprender mais de forma memorável e significativa, dessa forma, os alunos foram capazes de ver as conexões de sala de aula aprendendo a prática clínica e no mundo real.

Vários dos participantes mencionaram a importância dos alunos a melhorar o ato de escutar os pacientes. Essa habilidade foi discutido como falta ou desvalorizada no ensino convencional de abordagens de aprendizagem. Um participante com 7 anos de experiência com a Pedagogia Narrativa fez a seguinte declaração: Porque uma das coisas e, particularmente , acho que na nossa sociedade atual, "os alunos já não têm a habilidade de ouvir , porque eles estão nas mensagens de texto o tempo todo."

Este resultado se relaciona com os outros resultados descritos. Os alunos têm de ouvir histórias dos pacientes, entendê-las, através da prestação de cuidados individualizados. Durante a leitura de narrativas, estudantes ouviram atentamente. Chorando, risos e aplausos eram evidências de seu envolvimento. 
Os participantes relataram que alguns estudantes não parecem empenhados e alegou que este era uma ocorrência normal em qualquer ambiente de aprendizagem. Compreender conceitos / conteúdo onde todos os participantes discutiram o desejo para que os alunos se tornem mais bem informados de todo conteúdo dentro do curso. Este foi considerado como fundamental para os outros resultados identificados. Eles queriam que os estudantes usassem seu conhecimento para pensar criticamente e resolver problemas. Narrativas foram usadas para transmitir conteúdos específicos e os participantes queriam os alunos para transmitir a sua compreensão do conteúdo.

\section{Ser Comunicadores na Escrita e Oralmente}

Os participantes descreveram ambientes que eram colaborativa e propícia para a aprendizagem, desenvolvimento de habilidades de comunicação oral e escrita. Seu uso de Pedagogia Narrativa permitia aos alunos a participar em comunicação colaborativa através de discussões orais. Trabalhos escritos, como narrativas e estudos de caso, paradigma de estudantes, prática articular de seus pensamentos através da escrita. Alguns participantes usaram rubricas como um meio de transmitir expectativas de atribuição. Seus aspectos, como gramática, construção da história, sentença, fluência, detalhes narrativos, ortografia e clareza.

Um participante, com 3 anos de experiência com Pedagogia Narrativa, discutiu como ela era focada em melhorar as habilidades e com uma atribuição a escrita narrativa do aluno.

Os métodos e ferramentas representaram abordagens convencionais e não convencionais. Todos os participantes relataram o uso de métodos de avaliação convencionais e ferramentas em algum ponto dentro educação dos alunos formal para avaliar a aprendizagem dos conteúdos apresentados pela Pedagogia Narrativa.

Aqueles que viram Pedagogia Narrativa como uma filosofia abrangente usando diferentes tipos de métodos e ferramentas, em oposição àqueles que viram isso como uma estratégia. Quando perguntado sobre os desafios na avaliação da Pedagogia Narrativa, participante com mais de 10 anos de experiência efetivação e avaliação da pedagogia respondeu:

Eu não acho que é tão difícil assim. Eu não acho que o fato de que sua narrativa tornase mais difíceis de avaliar. Eu acho que às vezes faz com que seja mais difícil de descrever para outras pessoas que não o utilizam,mas,você sabe, eu vou colocar os nossos métodos de avaliação contra ninguém é em termos de sua clareza e eficácia. 
Elaborar e adicionar contraste a essa conta, outro participante com mais de 16 anos decretando Pedagogia Narrativa oferecia uma discussão sobre por que as ferramentas convencionais pode não ser a mais apropriada para avaliar o ensino ea aprendizagem em um ambiente de Pedagogia Narrativa.

Além disso, parte da pergunta pode incluir como você avalia o ensino ea experiência de aprendizagem para este tipo de ambiente e eu não acho que nós realmente temos um bom vocabulário para fazer isso. A seção a seguir descreve os métodos e ferramentas mais comuns utilizadas pelos participantes e suas conquistas e desafios com a determinação de métodos e instrumentos de avaliação adequados

As narrativas foram escritas para diversos temas a incluir experiências com pacientes em parada respiratória às questões éticas. Outras narrativas foram escritas para responder a perguntas como o que eu estou mais preocupado? O que é um enfermeiro? E como ensinar a ser enfermeiro? Muita dessas narrativas provocou discussão de preconceitos dos alunos e prévias experiências. A frequência destas atribuições variadas e muita vez ocorreu várias vezes ao longo do curso. Um participante com cinco anos na promulgação da Pedagogia Narrativa descrevia uma tarefa onde os alunos poderiam escolher para escrever sobre suas opiniões sobre o metaparadigma de enfermagem ou escrever uma "história que ilustrou os quatro grandes conceitos.".

Historicamente, os alunos optaram por escrever uma história contra simplesmente escrever as suas opiniões. Um participante discutiu como os professores também concluiram essas atribuições narrativas e compartilharam suas narrativas com os alunos, que ajudaram na construção de confiança e relacionamento dentro do ambiente de aprendizagem.

No geral, os participantes foram capazes de avaliar os estudantes através da escrita narrativa.

\section{De múltipla escolha e exames padronizados}

Todos os participantes relataram a avaliação por meio de algum tipo de múltipla escolha ou exame padronizado para avaliar a aquisição de conhecimentos. Um participante, com 2 anos de experiência na Pedagogia Narrativa, discutiu seu uso em exames de múltipla escolha para avaliar a aquisição de conhecimentos e pensamento crítico.

Se eles estão vindo acabar com a compreensão do conceito que foi ensinado, devem ser capazes de pensar criticamente sobre o assunto e ser capaz de responder à pergunta no exame. Eles também afirmaram que a Pedagogia Narrativa era capaz de preparar os alunos para ser bem sucedido nos exames de múltipla escolha e padronizado e muitas vezes referenciados. 


\section{Discussão em aula}

Todos os participantes relataram o uso de discussões em classe para avaliar formativamente os resultados da aprendizagem. Essas discussões variaram de sala de aula a discussão de aluno de suas experiências em ambientes clínicos para discussão on-line de problemas dos pacientes. Dois participantes descreveram como eles convidaram para visitar pacientes e discutir suas histórias relacionadas à família e saúde.

Os alunos entrevistaram os pacientes e discutiram seus problemas verbalmente. Os pacientes foram usados como ferramentas de ensino,bem como ferramentas de avaliação que permitiram que os participantes calibrassem como os alunos estavam pensando sobre os problemas dos pacientes e do conteúdo. Um participante que ensinou em um programa associado de graduação de enfermagem descrito em uma classe onde ela pediu aos estudantes para ler suas narrativas escritas: Você já viu algo comparável? Você concorda? Você discorda? Como podemos incorporar melhores condições para a nossa prática? O que você faria como um novo enfermeiro na medida em que o seguimento a qualquer situação foi apresentado na narrativa?

Discussões em classe revelaram se os alunos tinham entendido o conteúdo ou se novas indicações seriam necessárias. Essas discussões ocorreram com freqüência ao longo dos cursos e os alunos eram muitas vezes dados uma nota para refletir seu nível de participação. Um participante relatou a participação de $40 \%$ dos alunos.

\section{Discussão das Obras Literárias na Forma Verbal e Escrita}

Três participantes descreveram as atribuições baseadas em obras literárias. Um dos participantes, que ensinou em um programa de enfermagem, pediu aos alunos que leiam I Knew Mulher: Quatro mulheres Pacientes e seu cuidador Feminino, um livro escrito por uma enfermeira, Cortney Davis.

O livro discorre sobre a relação do profissional com quatro de seus pacientes. Outro participante, que ministrou um curso de pós-graduação em pediatria, pediu aos estudantes para ler O Espírito captura Você, por Ann Fadiman, um romance sobre uma criança com uma desordem de apreensão. Durante um curso sobre cultura, um participante iniciou uma discussão e fomentou os alunos a ler o mesmo livro, uma vez que relacionada a uma colisão de culturas entre comunidades e a comunidade médica. Os alunos deveriam ler dois ou três capítulos do livro a cada semana e, em seguida, discutiram suas leituras em sala de aula. 
Os alunos adoram, e não só, em seguida, abre possibilidades para entrar da narrativa para a história, mas também podemos trazer os princípios que estamos aprendendo, princípios de competência.

Os participantes foram capazes de avaliar se os alunos apreenderam conceitos e o conhecer desejado, resultados durante essas conversas de sala de aula.

\section{Estudos de Caso}

Dois participantes usaram casos paradigmáticos como ferramenta de avaliação de enfermagem. Estes não eram estudos de casos típicos, que incluiu apenas os dados biomédicos relacionados aos cuidados de um paciente. Os estudantes selecionados e um paciente completaram uma missão de quatro partes que incluiam: diagnóstico, terapêutica, educacional, e os planos de acompanhamento. Estes casos foram questões abrangentes e integrados para provocar a auto-reflexão dos alunos. Os alunos foram convidados a refletir sobre o que aprenderam a partir de um paciente em particular que possa afetar a sua prática, entre outras questões. O objetivo dessas ferramentas foi avaliar o pensamento dos alunos.

Os alunos são os primeiros a perguntar por que escolheram este caso para escrever eo que fez ensinar-lhes que eles nunca vão esquecer. Como ele vai mudar a sua prática? Esse é o inicio do papel do paradigma. Depois, há um guia para o paradigma que serve como o que está acontecendo aqui, o que é o tipo de fatores biológicos, psicossociais, de desenvolvimento e todos aqueles outros tipos de aspectos que possam estar em jogo para decidir o que fazer para o paciente.

\section{As auto-avaliações}

Cinco participantes pediram que os alunos completassem alguma forma de auto-avaliação, principalmente como método de auto-reflexão. Estas avaliações foram realizadas durante o curso e na conclusão do mesmo. Os participantes foram capazes de avaliar se os alunos estavam pensando criticamente sobre suas práticas profissionais e pessoais, os ganhos de aprendizagem e crenças. Um participante que ensinou fundamentos do curso de prática de enfermagem forneceu uma atribuição ao pensamento reflexivo onde os estudantes classificaram-se de 0 a 4 .

No final de cada aula, deixamos de lado alguns minutos para escrever. Eles respondem três perguntas: $\mathrm{O}$ que eu aprendi sobre enfermagem hoje? O que eu sei sobre enfermagem antes, mas agora entendo de uma maneira diferente? E sobre a aula de hoje é que eu ainda tenho dúvidas sobre ou eu ainda estou preocupado? . . . O que eles fazem é avaliar a sua participaçãoe que faz parte das quatro 
questões. . . Eu costumava ter um pressuposto de que os alunos que não estavam falando não estavam pensando, é por isso que eu comecei a tê-los a escrever no final da classe. Descobri que alguns dos estudantes que estavam mais tranquilos foram os estudantes que eram grandes pensadores.

Outros participantes relataram o uso de jornais, um plano de auto desenvolvimento, e questões reflexivas. Além disso, um participante perguntou aos alunos a refletir e escrever a sua filosofia pessoal de enfermagem. A maioria dos participantes usou avaliações clínicas para avaliar os resultados da aprendizagem. Primeiramente, as avaliações clínicas foram preenchidas por outros clínicos atribuídos como preceptores ou instrutores clínicos para os alunos.

A participante com mais de 10 anos da Pedagogia Narrativa relatou o quão importante são as avaliações clínicas para avaliar os resultados da aprendizagem dos alunos.

\section{Documentos dos participantes}

Durante as entrevistas, os participantes foram convidados a fornecer exemplos de seus alunos "Trabalhos enviados, roteiros e ferramentas de avaliação". Todos os participantes forneceram documentos que eles haviam discutido em como avaliar conteúdos abordados em um curso ou classe onde usaram a Pedagogia Narrativa.

As ferramentas mais comuns fornecidas eram narrativas escritas por estudantes. Todo o apresentado narrativo foram avaliados e classificados como parte da nota númerica do curso do aluno. A participante enviou duas narrativas que por ele rotulados como bem escrito. Um dos andares do aluno vividamente retratava eventos relacionados com uma questão ética e legal. A história era duas páginas e meia em comprimento e descreveu como colega enfermeira e amiga do estudante tentou esconder um erro de medicação.

A outra história de comprimento semelhante foi sobre como um estudante agiu como um advogado para uma paciente. O participante um laudo de enfermagem e classificando as narrativas sobre idéias / conteúdo, detalhes da história, organização, linguagem e fluência da sentença. Os alunos receberam uma pontuação de dois e cinco para cada categoria. Uma narrativa bem escrita, de acordo com a rubrica, foi um dos que apresentou estrutura hábil, língua confiante, habilidoso uso de transições, suspense, e claro senso de propósito.

Outra atribuição focada na filosofia de enfermagem. O participante enviado parâmetros de atribuição que deram aos alunos a escolha de escrever um papel de duas a três páginas sobre seus pontos de vista do metaparadigma de enfermagem ou escrevendo uma história que descreve um incidente que 
cristalizou suas crenças sobre enfermagem. O participante ainda solicitado o raciocínio dos alunos para sua escolha de atribuição e as suas percepções sobre a atribuição da enfermagem no dia a dia da saúde coletiva. Esta atribuição foi concluída uma vez e abrangeu $25 \%$ do curso de grau do estudante. O participante avaliou a narrativa para o quão bem ele ilustrado crenças dos alunos sobre os conceitos de pessoa, saúde, meio ambiente e enfermagem.

\section{Análise do Paradigmade Caso}

Os trabalhos de análise de paradigma do casoenviados eram uma longa e pormenorizada, um deles foi aproximadamente oito páginas de comprimento e inclui uma página de referências. Instruções pediram a estudantespara escrever uma auto-reflexão de seu progresso, forças, fraquezas, e um plano para a aprendizagem e reunião objetiva.

Além disso, os alunos foram convidados a incluir o diagnóstico, terapêutica, educacional e acompanhamento do plano. Os participantes avaliaram os trabalhos para a exposição do pensamento críticode diagnóstico, pensando na adequação do cliente, a precisão dos resultados, a colocação de dados, o uso de correto da terminologia, o uso de abreviatura correta, e inclusão de recursos relevantes.

\section{Estudo de caso II}

Os estudos de caso das amostras enviadas e dados de avaliação apresentados pelos pacientes, diagnósticos diferenciais, plano terapêutico, plano de ensino, e um plano de acompanhamento. Um participante declarou o caso ondeestudos são semelhantes aos casos paradigma, mas são menos narrativa e reflexiva.

Um participante enviou um documento que listou três perguntas reflexivas para que os alunos respondessem a cada dia durante uma base de curso de prática de enfermagem. Estas perguntas foram listados e discutidos anteriormente na seção de auto-avaliação deste capítulo.

\section{Discussão}

O objetivo deste estudo fenomenológico foi explorar as experiências de educadores que usaram Pedagogia Narrativa para ensinar conceitos de enfermagem e tópicos. Com base nas discussões dos 
participantes e dos documentos apresentados, o pesquisador foi capaz de entender melhor como o aprendizado após a promulgação da Pedagogia Narrativa foi avaliada e foi capaz de fazer algumas interpretações para começar a responder perguntas de pesquisa deste estudo. A presente discussão apresentará interpretações, implicações do pesquisador para o ensino de enfermagem e prática, limitações do estudo e recomendações da pesquisa futuras. Quais são os resultados de aprendizagem desejados na seguinte Pedagogia?

Embora na Pedagogia Narrativa convirjam várias pedagogias, incluindo a convencional, era evidente que os resultados desejados eram mais ricos e foi além das pedagogias convencionais na ênfase no desempenho de habilidades e aquisição de conhecimento. Enquanto os resultados comportamentais foram ainda importante para cada participante, todos enfatizaram o desenvolvimento das competências cognitivas e afetivas. Os resultados desejados vieram de domínios cognitivos e afetivos da aprendizagem. Inclusão desses domínios na escolaridade e aprendizagem é importante na preparação de alunos para serem preparados como profissionais de saúde no complexo ambiente imprevisível de saúde. As abordagens pedagógicas devem incorporar todos os domínios da aprendizagem de acordo com a Taxonomia de Bloom: cognitivo, psicomotor e afetivo (FALLAHI e LAMONACA, 2009).

Os participantes expressaram interesse nos alunos serem capazes de atingir vários resultados relacionados a pensar, comunicar, ouvir, tomar decisões éticas, proporcionando atendimento individualizado, e entender o conteúdo. No geral, os participantes estavam confiantes na capacidade dos alunos para atingir esses resultados através da Pedagogia Narrativa. Currículos de enfermagem centramse rotineiramente em objetivos comportamentais e resultados do domínio psicomotor (NLN, 2003).

No entanto, a prática de enfermagem envolve mais do que a conclusão de habilidades técnicas. Enfermeiros vão encontrar diversas questões dentro da saúde e deve ser capaz de pensar de forma criativa em situações complexas. Os três primeiros níveis de cognição, conhecimento, compreensão e aplicação, envolvem recordar principalmente, básica compreensão do conteúdo, e transferência de aprendizagem (FALLAHI e LAMONACA, 2009). Nestes níveis, os alunos são solicitados a dissecar o conteúdo, integrar conceitos de aprendizagem e formular julgamentos sobre o conteúdo (FALLAHI e LAMONACA), aquisição de conhecimento e compreensão.

Foi um resultado discutido por todos os participantes. Todos eles desejavam para os alunos desenvolverem uma profunda compreensão do conteúdo e aplicar o aprendizado em sala de aula para a prática de ambientes. Ensinar e aprender abordagens deve incorporar todos os níveis de cognição, especialmente os níveis mais elevados que representam níveis avançados de pensamento, tais como análise, síntese e avaliação.

De acordo com outros estudos, os resultados mostram que os participantes estavam confiantes em no uso da Pedagogia Narrativa para incentivar e melhorar diferentes tipos de pensamento 
(ANDREWS et al, 2001; CHAN, 2008; IRONSIDE, 2003 , 2004, 2006 ; SCHECKEL e IRONSIDE, 2006). Vários dos participantes foram além do resultado de enfermagem de rotina do pensamento crítico e incorporado estratégias para promover o raciocínio clínico e provocam interpretativas, multiperspectiva e reflexiva.

Estes tipos de pensamento ajuda revelar premissas tomadas como certas e possibilitar profissionais a tomar decisões clínicas baseadas no conhecimento científico, bem como necessidades do paciente individualizado. Profissionais que são capazes de efetivamente auto-reflexão pode ter mais autoconhecimento e ser capaz de reconhecer as áreas que necessitam de melhorias em suas práticas (SCHECKEL e IRONSIDE, 2006).

Scheckel e Ironside (2006) concluíram que a Pedagogia Narrativa proporciona a alunos e professores à oportunidade de participar no pensamento interpretativo. Brown e colegas (2009) relataram o resultado mais desejado seguinte da Pedagogia Narrativa foi melhoria de vários tipos de pensamento. Mesmo com diferentes entendimentos e encenações de Pedagogia Narrativa, todos os participantes "desejavam que os alunos melhorassem as suas capacidades cognitivas".

Os resultados deste estudo ilustram a criatividade utilizada pelos participantes na avaliação cognitiva dos resultados de aprendizagem. Todos os instrumentos de avaliação utilizados e discutidos pelos participantes habilitados para avaliar o funcionamento cognitivo dos alunos. A Pedagogia Narrativa complementa as pedagogias convencionais com as suas capacidades para promover maiores níveis de aprendizagem cognitiva e afetiva.

Os participantes que usaram Pedagogia Narrativa como uma estratégia de ensino alternativo parecem confiar em narrativas que enfatizem e ensinem conceitos e temas que exigiam a aprendizagem afetiva, tais como a defesa do paciente e comportamento ético. Estes participantes também usaram narrativas de conteúdo em que eles queriam provocar emoções dos alunos como examinar os medos e preocupações educacionais dos alunos.

Eles discutiram a incorporação da sensibilidade cultural e preocupações psicossociais, além de questões biomédicas dentro de sala de aula em discussão de narrativa. Como alegado por Young (2007),os participantes se sentiram como se narrativas retratadas uma imagem mais holística do tema, problema ou preocupação. Dados deste estudo sugerem que a Pedagogia Narrativa facilita a aprendizagem afetiva e melhor do que as pedagogias convencionais usadas sozinhas.

Como descobriu em estudos anteriores, a Pedagogia Narrativa proporciona um ambiente de aprendizagem que promove a exploração de conceitos como comportamento ético, a sensibilidade cultural, e dos alunos empatia (HUNTER, 2008; SENHORIAL, 2007; SHIEH, 2005). Os participantes descreveram ambientes personalizados e humanizados de aprendizagem que muitas vezes resultou em choro e riso. 
Vários participantes relataram estudantes chorando durante a leitura de narrativas. Como citado por Huntington e Gilmour (2001), as narrativas provaram serem poderosas ferramentas afetivas que encarnavam os pacientes e aprendizagem humanizada. Os alunos foram capazes de sentir empatia com o contador de histórias e personagens da história. Pacientes nas narrativas tornou-se mais do que sinais e sintomas tão frequentemente retratado em pedagogias convencionais. As narrativas escritas por estudantes, discussões em classe, discussões escritas de obras literárias, análises de caso paradigmático deram aos participantes os meios para avaliar os resultados da aprendizagem afetiva.

Um ato muitas vezes negligenciado, mas vital, é a habilidade em fornecer o cuidado centrado no paciente e a capacidade de ouvir eficaz. "Ouvir e ouvir o significado inerente em palavras é uma habilidade que a maioria da prática avançada em currículos de enfermagem que não abordam de forma sistemática" (SWENSON e SIMS, 2003, p. 180). Narrativas do paciente fornecem um portal para o enfermeiro entrar no mundo do paciente e compartilhar experiências. Os participantes promoveram o desenvolvimento da escuta, convidando pacientes reais para vir e ser entrevistado durante as reuniões de classe. A perícia também foi promovida através de discussão das narrativas dos alunos.

Comunicações orais e escritas oferecidas aos alunos deram melhores oportunidades para refinar habilidades de comunicação e colaboração. A ênfase dos participantes em desenvolvimento de habilidades de comunicação era evidente pelos vários tipos de trabalhos de escrita utilizados e a formulação de suas rubricas de classificação. De acordo com a literatura relacionada com a Pedagogia Narrativa, os alunos eram livres para discutir e desenvolver seus próprios significados e crenças de conteúdo, que ajudou a moldar sua prática profissional (CHAN, 2008; DIEKELMANN, 2001; SHIEH, 2005). Através da colaboração aberta, os alunos também aprenderam a respeitar os valores e crenças dos outros.

Quais os métodos e ferramentas de avaliação são mais adequados para medir os resultados dos alunos após a Pedagogia Narrativa? Mais discussão e dando ênfase aos os resultados desejados, em comparação com a avaliação de ferramentas e métodos. Participantes explicam que as ferramentas e os métodos convencionais podem ser adequados para avaliar determinados resultados de aprendizagem, tais como a aquisição de conhecimento e pensamento crítico.

Outros resultados de aprendizagem afetiva podem ser difíceis de avaliar cuidadosamente através de métodos convencionais e ferramentas. Isso ficou evidente com o uso de métodos alternativos, como a dos participantes com questionamentos auto-reflexivos, trabalhos escritos, e de discussões em classe. É importante notar que diferentes entendimentos de Pedagogia Narrativa vai influenciar a forma como ela é promulgada e avaliada. Como enfatizado por um participante, Pedagogia Narrativa empresta a vários métodos de execução de educação e assim sendo, "não é uma maneira errada de fazêelo." No entanto, é importante que os educadores proporcionem um diálogo aberto no ambiente que gera a 
comunidade e reúne vários pontos de vista e paradigmas em conversas, a fim de colher todos os benefícios dessa Pedagogia (DIEKELMANN , 2001).

O pesquisador observou que as diferenças mais significativas foram na compreensão dos participantes da Pedagogia Narrativa. Essas diferenças tiveram a maior influência para os resultados deste estudo. Aqueles que consideraram uma filosofia abrangente parecem pensar que a aprendizagem era de responsabilidade dos educadores e estudantes. Os educadores foram responsáveis por facilitar, orientar, e proporcionando um ambiente propício para a aprendizagem. No entanto, os alunos foram responsáveis pela sua própria aprendizagem e isso ficou evidente nos tipos de tarefas que exigiam que os estudantes fossem auto direcionados.

Os alunos foram responsáveis por determinar suas próprias metas de aprendizagem. Educadores e estudantes assumiram a responsabilidade em garantir se os alunos estavam progredindo em direção a seu objetivo de aprendizagem. Os alunos foram capacitados para determinar o que era importante para eles e sua prática de enfermagem. No fim do curso, os estudantes completaram uma auto-avaliação e, esta ação exemplifica aos estudantes a centralidade da Pedagogia Narrativa Em contraste, os participantes que viram a Pedagogia Narrativa como uma estratégia complementar parecia concentrarse mais sobre a cobertura do conteúdo e a garantia que os alunos aprenderam o que foi pré-determinado pelo professor como importante.

A responsabilidade de orientar a aprendizagem do aluno estava apenas com o professor. A Pedagogia Narrativa foi uma estratégia utilizada para melhorar a aprendizagem, uma vez que criou um contexto rico relacionado com a aprendizagem objetiva. Para continuar a reforma curricular, os educadores devem avaliar a sua compreensão e promulgação da pedagogia para garantir que eles estão enfatizando a aprendizagem para o desenvolvimento de profunda compreensão ao invés de ensinar o conteúdo para a memorização de curto prazo. Os dados apresentaram provas de vários tipos de instrumentos e métodos utilizados para avaliar após a promulgação da Pedagogia Narrativa. A maioria dos participantes relatou satisfação com os seus métodos ou ferramentas de ser apropriado para medir os resultados da aprendizagem.

Avaliação da Pedagogia Narrativa não apareceu muito diferente do que as pedagogias convencionais. Contudo, ferramentas alternativas, tais como auto-avaliações, deram aos participantes um maior conhecimento sobre como os alunos estavam pensando mais do que os métodos convencionais. Os participantes utilizaram vários métodos e ferramentas e considerado muitos fatores, como resultado a ser medido, o tamanho da classe, e tempo de avaliação, quando a seleção qual ferramenta utilizar. 


\section{Abordagem aberta}

É preciso experiência e confiança na pedagogia para ser capaz de orientar a aprendizagem do aluno e garantir que o conteúdo crítico é abordado em áreas de conteúdo específico. A pressão para manter a vontade limites de acreditação nacional de o educador abandonar estratégias de ensino e de avaliação considerado bem sucedido a adotar novas abordagens ou pedagogias.

Concentre-se sobre esses tipos de exames de influenciar as decisões pedagógicas dos educadores e dificulta a reforma da educação em enfermagem. Swenson e Sims (2000) também discutiram como a necessidade de preparar os alunos para exames de certificação tem influenciado negativamente a criatividade em programas de enfermagem, como educadores relutam em se afastar de pedagogias convencionais e adotar nova alternativa pedagogicas.

Implicações para os professores de enfermagem que querem adotar novas pedagogias, para melhor preparar os alunos para prática de enfermagem através da Pedagogia Narrativa. Os resultados deste estudo fornecem evidência à utilidade da Pedagogia Narrativa no ensino de enfermagem.

A pedagogia pode ser utilizado para complementar pedagogias convencionais ou estratégias de ensino como complementares para conteúdo específico de áreas. Além disso, é uma filosofia de ensino que cria um ambiente ideal para aprendizagem dos alunos. Ao promulgara Pedagogia Narrativa, todos os participantes relataram que os alunos e professores estavam ativamente engajados em um ambiente colaborativo.

Educação centrada no aluno está na vanguarda da enfermagem na reforma de currículos. Os alunos são mais responsáveis pela sua própria aprendizagem, que produz autodidatas que são automotivados. Eles são capazes de oferecer entrada que moldasuas experiências de aprendizagem. O ambiente aberto da narrativa permite que os alunos formulem suas próprias idéias e verdades da instrução enquanto ser consciente de forças opressivas e influências culturais, sociais e políticos (DIEKELMANN, 2001). Alunos preparados em Ambiente de Pedagogia Narrativa será mais poder sobre a sua aprendizagem, que deverão levá-los a questionar e melhorar outros aspectos de seu mundo, incluindo a prática de enfermagem.

Além disso, a Pedagogia Narrativa personaliza ambientes de aprendizagem que ajudam os pacientes de forma humanistica por um currículo focado na biomédica, livros de Enfermagem apresentam frequentemente a perpetuação da dominação médica, enfatizando diagnósticos médicos e as manifestações clínicas enquanto acontece a descentralização do paciente (HUNTINGTON e GILMOUR, 2001). Por estarem decretando Pedagogia Narrativa como uma filosofia global de ensino, comportamentos opressivos perpetuados, alguns inadvertidamente, através da educação convencional pode ser reduzida ou eliminada. 
Além disso, os resultados deste estudo devem ajudar educadores interessados em Pedagogia Narrativa selecionar as ferramentas de avaliação, encontrar recursos relacionados com a avaliação de Pedagogia Narrativa, ou criar novas ferramentas ou métodos. Deve notar-se que a Pedagogia Narrativa não era difícil de avaliar com métodos e ferramentas convencionais. Os participantes forneceram detalhes de outros métodos e ferramentas, tais como trabalhos de análise caso paradigmático e narrativo escrito por estudantes. Discussões em classe simples provou ser uma importante ferramenta de ensino e de avaliação utilizado por todos os participantes. Educadores poderiam incorporar as discussões em classe de narrativas escritas por estudantes para promover interpretativo e multiperspectiva pensando ao mesmo tempo em ensinar uma variedade de temas e conceitos.

Os alunos preparados através da Pedagogia Narrativa tornam-se melhores ouvintes e estão atentos as histórias de pacientes, questões, e necessidades dos mesmos. Igualmente importante, é a capacidade desses alunos a reconhecer os pontos comuns em todas as histórias dos pacientes. Os alunos aprendem a assistir as histórias dos pacientes enquanto as escutam para ser compartilhada em edições originais.

\section{Conclusão}

O ambiente complexo de saúde cria um desafio para os currículos de enfermagem para se adaptar às suas constantes mudanças. Licenciados em Enfermagem devem estar preparados para prestar cuidados complexos adiversos pacientes. A Pedagogia Narrativa é uma pedagogia baseada em evidências desenvolvidas durante um estudo de pesquisa. Essa abordagem de ensino e aprendizagem combina pedagogias de múltiplass abordagens e fornece algumas soluções para as questões que envolvem currículos de enfermagem (DIEKELMANN, 2001; NEHLS, 1995).

Há poucos dados na literatura detalhando como medir adequadamente aprendizagem e resultados alcançados através da Pedagogia Narrativa. Este estudo utilizou a fenomenologia heideggeriana e análise hermenêutica de entrevistasde oito educadores de enfermagem "para entender melhor como eles avaliavam a Pedagogia Narrativa". Os resultados deste estudo mostraram que o ensino centrado na narrativa e aprendizagem é capaz de preparar os alunos com as habilidades cognitivas e afetivas necessárias para bem transição da academia para a prática. A Promulgação dos participantes e avaliação de Pedagogia Narrativa foi influenciada por sua compreensão dele como uma filosofia global versus uma estratégia de ensino complementar.

Os participantes esperados e os estudantes alcançaram resultados mais ricos através da Pedagogia Narrativa em comparação com os pedagógicos convencionais. Estes resultados foram 
diversos e necessários para a compreensão de níveis mais elevados do funcionamento cognitivo e afetivo.

Uma variedade de ferramentas foi usada para avaliar adequadamente a pedagogia, incluindo ferramentas convencionais. A maioria dos participantes manifestou-se satisfeito com os seus métodos de avaliação e / ou ferramentas. Seus documentos de discussão e exemplo fornecidos ricos em detalhes de como avaliar os muitos resultados de aprendizagem obtidos através da Pedagogia Narrativa. Mais importante ainda, osparticipantes ofereceram idéias valiosas sobre como avaliar os resultados da aprendizagem que são inadequadamente avaliadas através de métodos e ferramentas convencionais, como de várias perspectivas de pensar, ouvir, e comunicar.

As limitações deste estudo começam com a falta de uma definição estritamente definido de Pedagogia Narrativa. O pesquisador encontrou utilidade nos resultados que destacaram as diferenças. No entanto, os futuros pesquisadores deste tema podem ser úteis para reduzir a sua definição de Pedagogia Narrativa e refinar as linhas de investigação para refletir dos participantes a compreensão da pedagogia. Outra limitação incluía a ausência de diversos participantes, tais como as minorias e os machos, que podem ter diferentes interpretações da Pedagogia Narrativa.

Ficou comprovado que a Pedagogia Narrativa tem grande influência na nova perspectiva de abordagem do aprendizado, onde o aluno é estimulado a pensar, criticar, desenvolver habilidades e técnicas para o aperfeiçoamento da sua formação teórico-acadêmica na transformação da sua prática através das experiências vividas em ambiente escolar e social, favorecendo assim um melhor atendimento ao seu paciente numa abordegem holística de atenção à saúde. E em contrapartida, o profissional da educação se realiza na sua plenitude em sentir no atendimento prestado por seu aluno, a satisfação e a gratidão do paciente aos cuidados oferecidos pelo seu aluno.

Como forma sugestão para a introdução de práticas pedagógicas narrativas nos cursos de enfermagem seguem algumas recomendações:

- Introduzir como forma de readaptar o currículo do curso de enfermagem, para que os novos profissionais venham a ter um conhecimento mais prático das atividades a serem desenvolvidas, capacitando os professores a desenvolver uma estratégia inovadora de transmissão de conhecimentos através da introdução de técnicas que possibilitem o uso do raciocínio críticoreflexivo para facilitar o papel multidisciplinar na elaboração de cuidados integrais ao ser humano;

- Elaborar instrumentos capazes de avaliar não somente o conteúdo administrado em sala, mas como os alunos desempenham suas atividades extracurriculares, através da qualidade do serviço ofertado, do envolvimento com o indivíduo, comunidade e família, fortalecendo assim a pedagogia narrativa; 
- Elaborar critérios de seleção de professores levando principalmente em consideração a didática do docente, e não só por ser um detentor do saber, mas como um facilitador que fomente as vivências como fator primordial da aprendizagem, estimulando o aluno a pensar, criticar, pesquisar e transformar seu conhecimento em algo capaz de modificar a sociedade.

\section{Referências}

ANDREWS , CA, Ironside, PM, Nosek , C., Sims , LL, Swenson, MM , Yeomans, C. , Young, P. K. , \& Diekelmann, N. (2001 ). Promulgar Pedagogia Narrativa: as experiências vividas estudantes e professores. Cuidados de enfermagem e de saúde Perspectiva, 22 (5) , 252-259.

BENNER, P. (1994). Fenomenologia interpretativa:Encarnação, carinho e ética em saúde e doença.Thousand Oaks, CA: Sage Publications. Benner, P., Sutphen, M., Leonard, V.,\&Day, L. (2010). Educar enfermeiros: Um apelo à radical transformação. San Francisco: Jossey- Bass.

BROWN, ST, Kirkpatrick, MK,Greer, A., Matthias, AD, e Swanson, MS (2009). O uso pedagogias de inovadoras no ensino de enfermagem: uma perspectivainternacional. Enfermagem Perspectivas de Educação, 30 (3), 153-158.

CRIST, J. D., e TANNER, C. A. (2003). Métodos Interpretação / análise em interpretativa hermenêutica fenomenologia. Pesquisa em Enfermagem, 52 (3),202-205.

DIEKELMANN, N. (2001). Pedagogia Narrativa: análises hermenêuticas heideggeriana da duração experiências dos alunos, professores e médicos.Avanços em Ciências de Enfermagem, 23 (3) , 53 - Diekelmann , N. (2002) )."

DIEKELMANN, N.; DIEKELMANN, J. (2009). Escolaridade ensino aprendizagem: Rumo a Pedagogia Narrativa. Bloomington, IN: iUniverse .

DIEKELMANN, N., \& Smythe, E. (2004). Cobrindo o conteúdo eo currículo viciante: Como pode Eu uso o meu tempo com os alunos para melhor ajudá-los a aprender o que eles precisam saber? Journal of Educação em Enfermagem,43 (8), 341-344.

FALLAHI, C. R., e LAMONACA, F. H., Jr. (2009). A evolução dos objetivos educacionais: Bloom taxonomia e além. Jornal de Excelência em College Ensino, 20 (1),71-86.

HUNTER, L. A. (2008). Histórias como padrões integrados de saber no ensino de enfermagem. International Journal of Nursing Education Scholarship, 5 (1), 1-13. Huntington, A. D., \& Gilmour, J. A. (2001).Repensando representações, reescrevendo textos de enfermagem:Possibilidades através do pensamento feminista e foucaultiano. Journal of Advanced Nursing, 35 (6), 902-908.

IRONSIDE, P. M. (2003a). Novas pedagogias de ensino do pensamento: as experiências vividas alunos e professores articulado pedagogia narrativa. Journal of Nursing Education, 42 (11), 509- 
516. Ironside, P. M. (2003b). Tentar algo novo: Implementação e avaliação de Pedagogia Narrativa: Usando uma abordagem multi-método. Enfermagem Educação Perspectivas, 24 (3).

IRONSIDE, P. M. (2004). "Cobrindo conteúdo" e ensinar a pensar: Desconstruindo o aditivo currículo. Journal of Nursing Education, 43(1), 5-9.

IRONSIDE, P. M. (2006). Usando pedagogia narrativa: Aprender e praticar o pensamento $\begin{array}{llllll}\text { interpretativo.Journal of } & \text { Advanced } & \text { Nursing, } & 55 & \text { (4), } 486 .\end{array}$

IRONSIDE, PM, scheckel , M., Wessels , C., Bailey , ME, Powers, S., \& Seeley , D. (2003).

POLIT, D. F.,e BECK, C. T. (2008).Enfermagem pesquisa: Geração e avaliação das provas da prática de enfermagem.Philadelphia: Lippincott Williams \&Wilkins.

SCHECKEL, M. M., e IRONSIDE, P. M. (2006).Cultivar o pensamento interpretativo através decretando pedagogia narrativa. Enfermagem Outlook, 54, 159-165.

SHIEH, C. (2005). Avaliação de um método de ensino clínico envolvendo histórias. Internacional Revista de Educação em Enfermagem Scholarship, 2 (1) , 1-13.

SWENSON, M. M., e SIMS, S. L. (2003). Ouvir para aprender. Em N. L. Diekelmann (Ed.) Ensino. Os praticantes de atendimento: Novas pedagogias para as profissões de saúde (154-193). Madison,Wisconsin: The University of Wisconsin Press. EUA Census Bureau. (2008). Um país mais velho e mais diverso em meados deste século. Retirado dehttp://www.census.gov/newsroom/releases/archives/population/cb08123.htm

YOUNG, L. E. (2007).Baseado em história de aprendizagem: Misturando o conteúdo eo processo de aprender em enfermagem.

\section{Como citar este artigo (Formato ABNT):}

TEIXEIRA, Fabiano Martins. Avaliação da Pedagogia Narrativa no Curso de Bacharelado em Enfermagem na Universidade Regional do Cariri - URCA. Id on Line Revista Multidisciplinar e de Psicologia, 2017, vol.11, n.38, p. 295-321. ISSN: 1981-1179.

Recebido: 26.10 .2017

Aceito: 27.10 .2017 